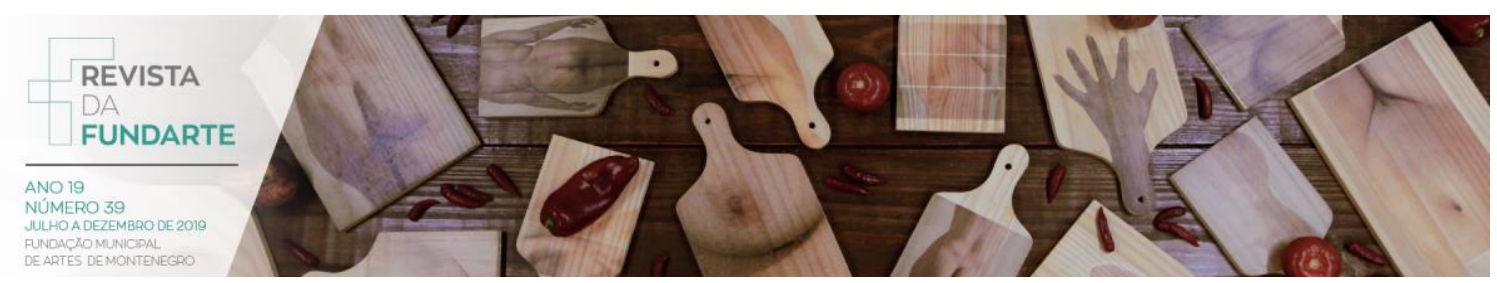

\title{
OLHAR A SI, OLHAR O OUTRO: AÇÃO EDUCATIVA NA EXPOSIÇÃO ATRAVÉS DA IMAGEM - ANO CINCO
}

Aline Kauana Cezar Adriana Lanzer de Oliveira

Patriciane Born

CEZAR, Aline Kauana; OLIVEIRA, Adriana Lanzer de; BORN, Patriciane Born. Olhar a si, olhar o outro: ação educativa na exposição através da imagem - ano cinco. Revista da FUNDARTE, Montenegro, p.222-228, ano 19, no 39, julho/dezembro de 2019.

Disponível em: http://.seer.fundarte.rs.gov.br/index.php/RevistadaFundarte/index> 20 de dezembro de 2019. 


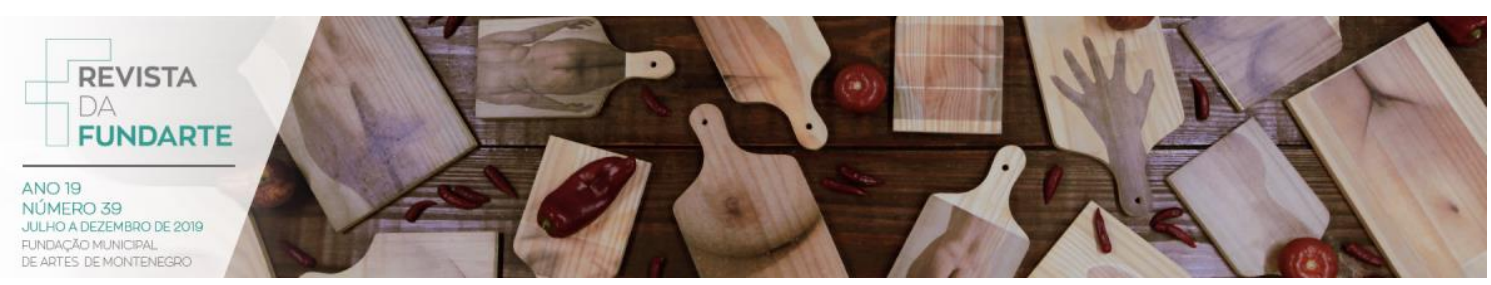

\title{
OLHAR A SI, OLHAR O OUTRO: AÇÃO EDUCATIVA NA EXPOSIÇÃO ATRAVÉS DA IMAGEM - ANO CINCO
}

\author{
Aline Kauana Cezar ${ }^{1}$ \\ Adriana Lanzer de Oliveira ${ }^{2}$ \\ Patriciane Born ${ }^{3}$
}

\begin{abstract}
Resumo: Este relato desenvolve-se a partir de experiências de mediações e ações educativas, narradas por integrantes da Rede de Mediadores, na exposição Através da Imagem - ano cinco, ocorrida na Galeria de Arte Loide Schwambach - Fundação Municipal de Artes de Montenegro FUNDARTE em agosto e setembro de 2019.

Palavras-chave: Mediação; Ação educativa, Rede de Mediadores, Arte contemporânea.
\end{abstract}

\section{EXPOSURE THROUGH THE IMAGE - YEAR FIVE}

Abstract: This narrative is developed from experiences of mediations and educational actions, narrated by members of the Rede de Mediadores (Network of Mediators), in the exhibition Através da Imagem - ano cinco, held at Galeria de Arte Loide Schwambach - Fundação Municipal de Artes de Montenegro - FUNDARTE during August and September 2019.

Keywords: Mediation, Educational action, Network of Mediators, Contemporary art.

A quinta edição da exposição Através da Imagem, que ocorreu entre 15 de agosto e 19 de setembro de 2019 na Galeria de Arte Loide Schwambach da FUNDARTE, reuniu três artistas, mulheres, que trabalham com fotografia e arte

\footnotetext{
${ }^{1}$ Arte-educadora, formada em Artes Visuais pela Universidade Estadual do Rio Grande do Sul (UERGS), atualmente graduanda em dança na UERGS. Participou do projeto de extensão Teatro e suas abordagens pedagógicas (TAP), é participante do projeto de pesquisa "Infraordinários", pela Uergs sob a orientação da professora doutora em Artes Visuais Mariana Silva, e é mediadora voluntária do Projeto Rede de Mediadores da Galeria de Arte Loide Schwambach - FUNDARTE.

2 Arte-educadora, formada em Gestão Cultural pelo Instituto Federal Sul-rio-grandense. Graduanda em Licenciatura em Dança na Uergs. Atua como professora bolsista na Escola Estadual de Ensino Fundamental Adelaide Sá Britto, em Montenegro/RS, desenvolvendo e aplicando projetos de dança pelo Programa Institucional de Bolsa de Iniciação Científica (PIBID). Mediadora voluntária na Rede de Mediadores da Galeria de Arte Loide Schwambach - FUNDARTE. Pesquisadora voluntária no projeto "Salas - edição 3", do Grupo de Pesquisa Flume Educação e Artes Visuais (Uergs/CNPq). Participante do projeto de extensão em dança Diversos Corpos Dançantes da UFRGS.

3 Professora, artista e mediadora. Atua como professora do Curso Básico de Artes Visuais da FUNDARTE, coordenadora da Galeria de Arte Loide Schwambach, bem como do Projeto Rede de Mediadores, desde 2010. É mestre em Educação e especialista em Pedagogia da Arte pela Universidade Federal do Rio Grande do Sul - UFRGS, licenciada em Artes Visuais pela Universidade Estadual do Rio Grande do Sul - UERGS. Desde o início de sua formação, participa de cursos, oficinas, seminários, palestras e conversas na área de artes visuais e educação, como ouvinte, professora convidada ou integrante da comissão organizadora, bem como participou de exposições coletivas e do coletivo de artistas Ponto de Fuga, tendo realizado projetos artísticos em parceria com a artista Michele Martines.
}

CEZAR, Aline Kauana; OLIVEIRA, Adriana Lanzer de; BORN, Patriciane Born. Olhar a si, olhar o outro: ação educativa na exposição através da imagem - ano cinco. Revista da FUNDARTE, Montenegro, p.222-228, ano 19, no 39, julho/dezembro de 2019.

Disponível em: http://.seer.fundarte.rs.gov.br/index.php/RevistadaFundarte/index $>20$ de dezembro de 2019. 


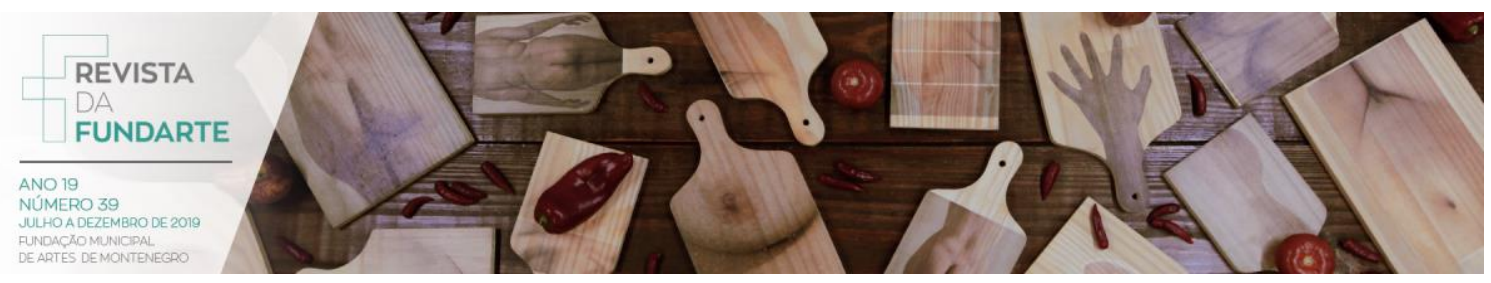

contemporânea. Duas delas, Bruna Engel e Ursula Jahn, são artistas locais, e Mariane Rotter, também organizadora do projeto Através da Imagem e curadora da exposição, vive em Porto Alegre e trabalha em Montenegro como professora da Graduação em Artes Visuais - licenciatura da Uergs.

A Rede de Mediadores ${ }^{4}$ da Galeria, que neste ano pode ser chamada de Rede de Mediadoras já que é composta somente por mulheres, planejou as mediações e ações educativas durante suas reuniões semanais ou quinzenais e também a partir de uma conversa com as artistas, momento em que aconteceu fértil troca e ampliação de suas poéticas, antes acessadas apenas pelos portfólios. As ações planejadas giraram em torno de palavras como: autoimagem, reflexo, ponto de vista, mulher, feminino, invisibilidade e cotidiano.

Os relatos aqui presentes se dão a partir de mediações com adolescentes dos Cursos Básicos de Artes Visuais e de Ballet Clássico da FUNDARTE. Uma das primeiras obras a ser abordada era a série de fotografias intitulada "O sofá", de Bruna Engel que, em suma, documenta a experiência dos recém mãe e pai e da mudança que se instaura na rotina da casa a partir da chegada de um/a filho/a. Questões presentes como o registro do cotidiano e a (falta de) espontaneidade na fotografia foram o convite para a primeira ação. Sem falar nada, após observarem as obras foi perguntado:

- Vamos fazer uma foto?

E o celular era tirado do bolso para registrar os corpos que, a partir daquele momento, modificavam. A naturalidade dava espaço para poses, fotos posadas. Os corpos alteravam sua forma e como ocupavam o espaço, adotavam uma postura já pensada para a fotografia. Depois dessa experiência, vivida, e não só falada - o que é importante mencionar, uma vez que as ações educativas são pensadas também de forma que se experiencie, deslocando quem frequenta a galeria de arte desse

\footnotetext{
${ }^{4}$ No presente ano, integram a Rede de Mediadores: Adriana lanzer de Oliveira, Aline Kauana Cezar, Jacinta Griebeler, Jéssica Pinheiro, Larissa Borges, Patriciane Born, Rosemari Fiuza e Susana Toledo, todas graduandas ou graduadas em licenciatura em Artes Visuais e/ou Dança pela Universidade Estadual do Rio Grande do Sul - Uergs.
}

CEZAR, Aline Kauana; OLIVEIRA, Adriana Lanzer de; BORN, Patriciane Born. Olhar a si, olhar o outro: ação educativa na exposição através da imagem - ano cinco. Revista da FUNDARTE, Montenegro, p.222-228, ano 19, ํo 39, julho/dezembro de 2019.

Disponível em: http://.seer.fundarte.rs.gov.br/index.php/RevistadaFundarte/index $>20$ de dezembro de 2019. 


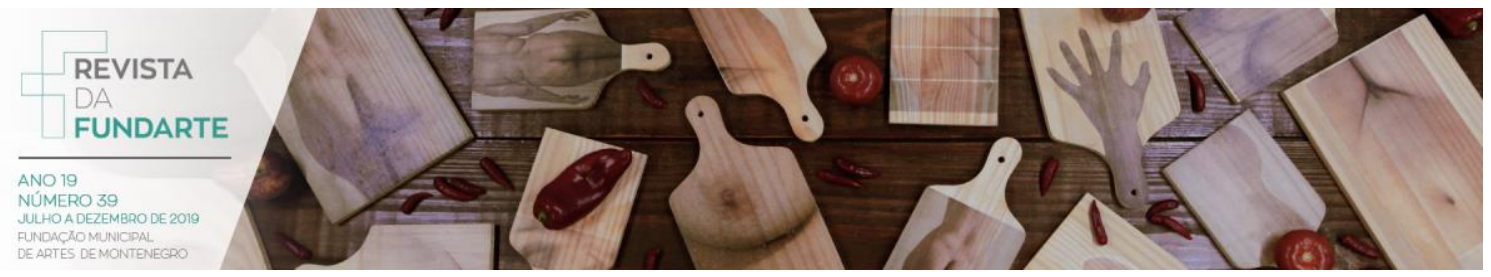

lugar de passividade - os/as estudantes começavam a se relacionar de forma diferente com os trabalhos expostos.

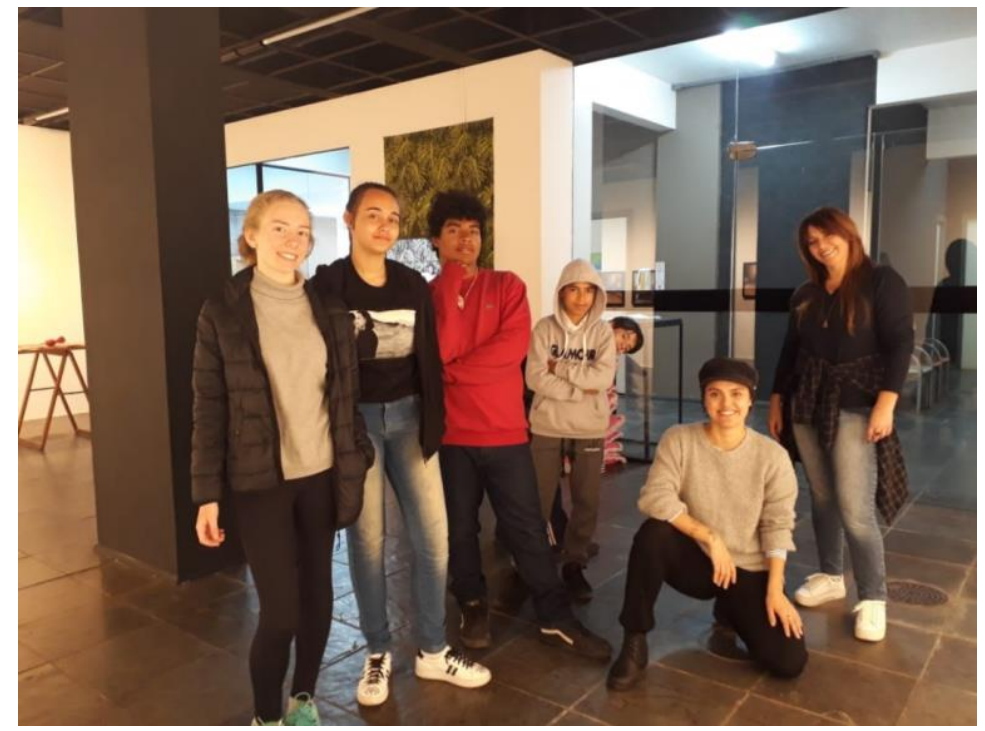

Seguindo para o trabalho de Mariane Rotter, "Meu ponto de vista: checkin/check-out", uma série de autorretratos em espelhos de banheiros públicos e privados, uma linha se formava em frente aos quadros pendurados. O nível mais baixo das obras chamavam a atenção das alunas e alunos que também podiam se ver (ou não) refletidos no vidro. Esse reflexo foi um dos gatilhos para pensarmos duas ações. A primeira, propor a investigação do espaço, das obras, dos colegas, de si, através de um espelho. Como me vejo? Como vejo o outro? Como se dá a experiência em olhar diretamente ou por intermédio de algo ou alguém?

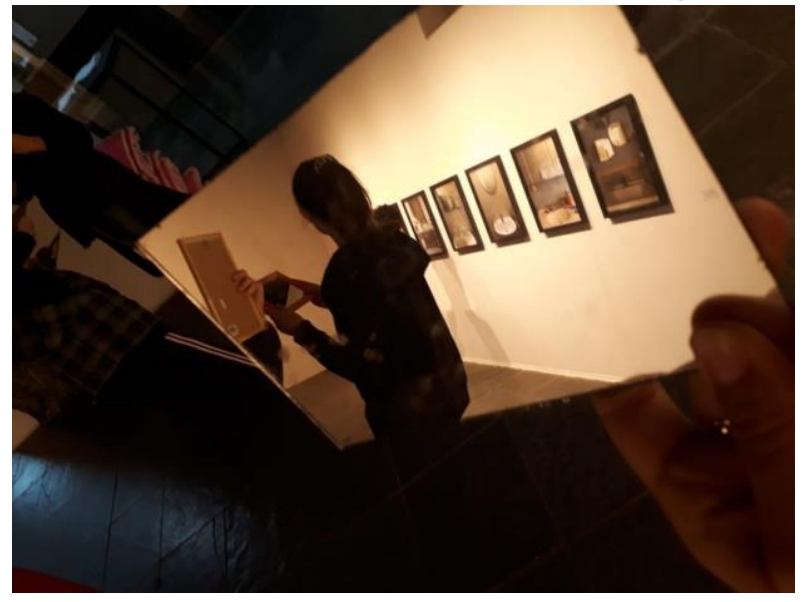

CEZAR, Aline Kauana; OLIVEIRA, Adriana Lanzer de; BORN, Patriciane Born. Olhar a si, olhar o outro: ação educativa na exposição através da imagem - ano cinco. Revista da FUNDARTE, Montenegro, p.222-228, ano 19, ํo 39, julho/dezembro de 2019.

Disponível em: http://.seer.fundarte.rs.gov.br/index.php/RevistadaFundarte/index $>20$ de dezembro de 2019. 


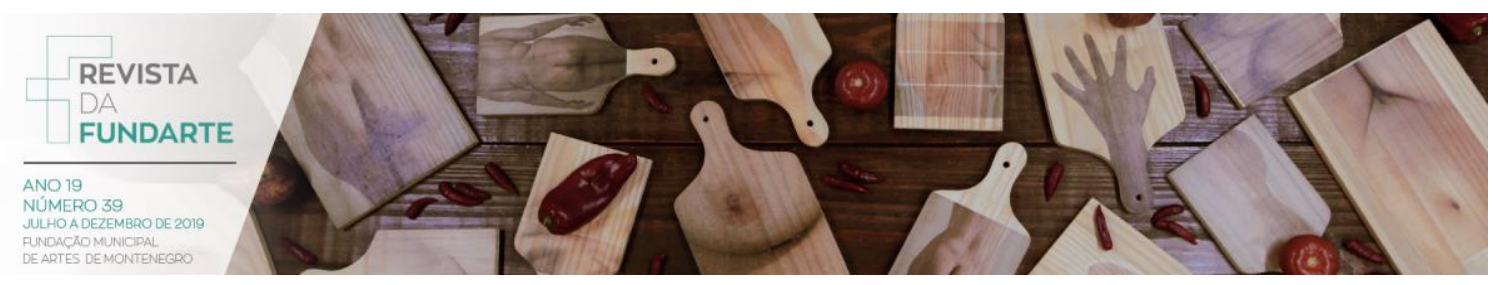

A outra ação aconteceria em uma sala-ateliê, em que os alunos desenhariam uns aos outros através do vidro, sob uma folha plástica transparente. (In)visibilidade, percepção. Quais corpos foram pensados para a construção desses espaços? E quais são os corpos que ocupam esse espaço? Você se enxerga? Como? As perguntas propositivas os instigam e faz com que revisitem nos lugares físicos e também na memória aqueles espaços em que não se sentiram incluídos, vistos.

A instalação de Ursula Jahn, "À la carte", composta por tábuas culinárias com impressões fotográficas de partes do corpo sob a mesa, era um convite para reunirmo-nos em volta dela para falar sobre as questões mais delicadas. Nesse momento, o que no início eram falas tímidas, tornavam-se potentes à medida que cada uma que estava presente compartilhava sua história e informações sobre como é ser mulher. Ser mulher aos 14, 24 ou aos 45 anos é continuar resistindo e lutando por seu lugar de fala, de trabalho. Os e as estudantes, em grande parte mulheres, reuniram-se em volta da mesa para olhar aquilo que retrata como éramos vistas: pedaços de carne. Com certeza um dos momentos mais especiais das mediações eram as trocas que aconteciam ao redor daquela mesa.

Da galeria para a sala. Lá, dividimos dois grupos, aqueles que desenhariam e aqueles que posariam do outro lado da janela. Após, os grupos alternavam e quem era o desenhista se tornava o modelo. A proposição era usar outros suportes, materiais, maneiras de se fazer e de experienciar novas formas de se ver e ver o outro. Desenhar parece simples, mas a atividade vai além de um simples desenho. Propõe a quem participa olhar para o outro. E talvez seja mais ousado: manter o olhar. Procurar os detalhes, as características, aquilo que faz quem está sendo desenhado identificar-se com a imagem, ou não, afinal o olhar do outro não é exatamente aquilo que vemos no espelho, é grande parte construído em cima das informações que já existem em quem desenha, perpassa pela forma de como somos vistos pelo outro.

CEZAR, Aline Kauana; OLIVEIRA, Adriana Lanzer de; BORN, Patriciane Born. Olhar a si, olhar o outro: ação educativa na exposição através da imagem - ano cinco. Revista da FUNDARTE, Montenegro, p.222-228, ano 19, ํo 39, julho/dezembro de 2019.

Disponível em: http://.seer.fundarte.rs.gov.br/index.php/RevistadaFundarte/index $>20$ de dezembro de 2019. 

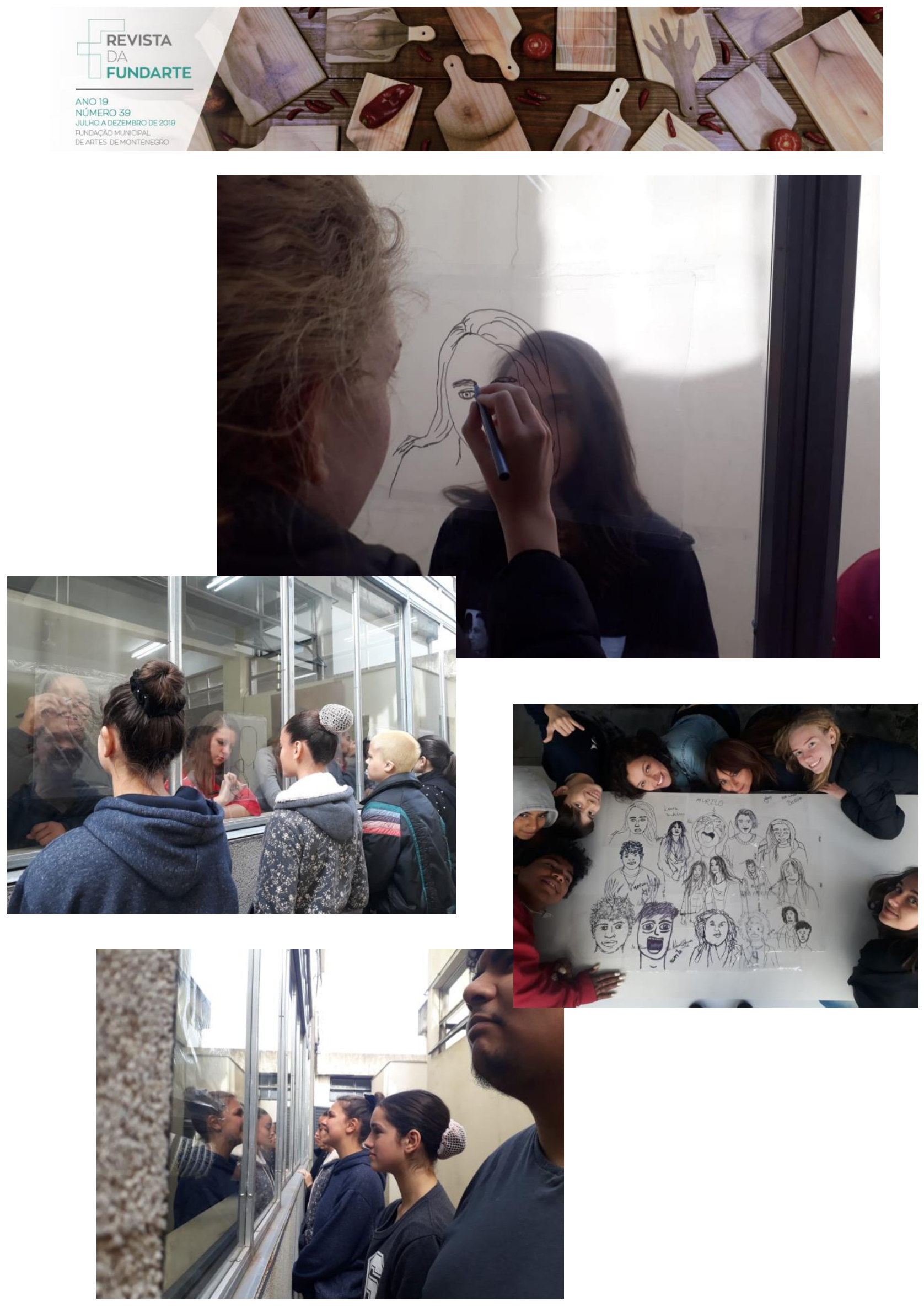

CEZAR, Aline Kauana; OLIVEIRA, Adriana Lanzer de; BORN, Patriciane Born. Olhar a si, olhar o outro: ação educativa na exposição através da imagem - ano cinco. Revista da FUNDARTE, Montenegro, p.222-228, ano 19, no 39, julho/dezembro de 2019.

Disponível em: http://.seer.fundarte.rs.gov.br/index.php/RevistadaFundarte/index $>20$ de dezembro de 2019. 


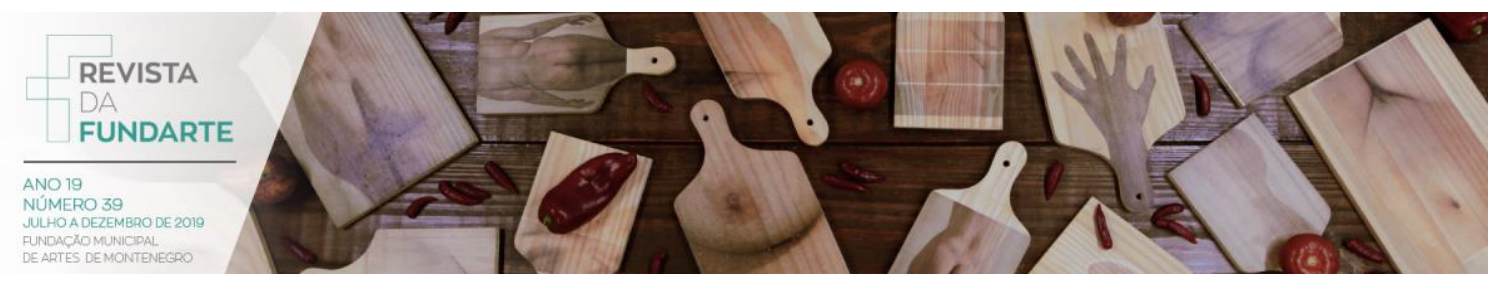

Essas ações, assim como outras planejadas pela Rede de Mediadores a cada exposição, buscam não trazer respostas, mas sobretudo motivar perguntas. Aquilo que é dado como verdade absoluta, (im)posto, aquilo que nos disseram que deveria ser, pode obstruir o que nestes dias anda tão em falta: criar novas possibilidades do pensar. Propor experiências a partir de uma exposição de arte faz com que quem está ali, dentro da galeria, possa levar consigo as sensações e questionamentos vividos para outros espaços e compará-los, e também fazer novos. Tais ações (des)educativas podem ser um impulso para pensar em arte não só como algo estático, mas aquilo que também propõe movimento. Um impulso para olhar, de novo e de novo, a si e para o outro.

CEZAR, Aline Kauana; OLIVEIRA, Adriana Lanzer de; BORN, Patriciane Born. Olhar a si, olhar o outro: ação educativa na exposição através da imagem - ano cinco. Revista da FUNDARTE, Montenegro, p.222-228, ano 19, no 39, julho/dezembro de 2019.

Disponível em: http://.seer.fundarte.rs.gov.br/index.php/RevistadaFundarte/index $>20$ de dezembro de 2019. 